\title{
Research and analysis of social obstacles in college students
}

\author{
Long Yin, Datao Wu and Yue Fu
}

School of economics, Harbin University of Commerce, Harbin 150028, China

Keywords: social obstacles, college students, rooted theory.

\begin{abstract}
Social disorder characterized by social disorder with people (especially in public occasions), involuntarily feel nervous, afraid, and so unprepared, incoherent, serious and even afraid to see people, often called social phobia, social phobia, is a kind of to feel intense fear or any social or public concerns of mental illness.Today's college students' social barriers is the most common mental problems in college students, in order to further understanding the reason of college students' social obstacles, so as to help more students solve the problem of social disorder, we use the interview and questionnaire survey method to collect a large amount of data, survey we use grounded theory on the basis of the thought method has carried on the preliminary interview and questionnaire design.In this article, through the analysis of data, and the research on college students' social dysfunction process are analyzed.Thus concluded that the causes of college students' social barriers and puts forward the solution.
\end{abstract}

\section{The purpose and meaning of project research}

Man is a social creature, and in today's highly advanced society, people must learn to communicate with others. Psychological socialization theory, the life of each stage are regarded as the key stage of "the crisis and chance", while the fifth stage of life, the youth phase is the key of the key. For college students really such a stage, at this stage in the college students suffer from psychological and physiological, the pressure from all aspects of the society, family, if you can't very well to release the pressure, will have a significant impact on the mental health of college students. While having healthy and healthy social skills is the best way for college students to release stress, bad social interaction can be a threat to college students' mental health. Unhealthy psychological problems in college students lead to a range of behaviors and thoughts. Therefore, it is important to find out the factors that influence the normal social interaction of college students and guide the healthy development of psychological network of college students.

The purpose of the project. (1) Understand the social barriers of college students: The causes of social disturbance of college students are multi-faceted, which mainly consists of the college students' own defects and the external environment. The defects include physical and psychological defects, including social environment, family environment and campus environment. Especially, with the rapid development of the society in recent years and the rise of all kinds of social media, college students using social networking, too much make yourself in a state of relatively closed, social disorder problem increasingly prominent.(2) Combining research results to analyze the causes of social disorders in college students: The reasons for college students' social problems are manifold. For example, the modern developed network makes the communication between college students and students online, which leads to the lack of real communication experience and social barriers for college students. If the bad family environment has bad effect on the psychology of college students, it produces a sense of consciousness and is not willing to communicate with others. There are such as the contradiction between modern social utilitarianism and traditional beliefs, the influence of the exam-oriented education, the gap between rich and poor, its defects, such as the disabled, etc.), all communication has a bad influence to the health of college students, so that the students have communication disorders, poor communication and can make college students' personality extreme triggering more unpredictable consequences.(3) Find ways to help college students overcome social barriers: Project on the basis of the investigation of present situation of college students' social obstacles, combined with college students' social barriers of many factors, finally put forward 
targeted overcame the obstacle of college students' social interventions. To make college graduates better integrate into society and realize their own value.

The significance of the implementation of the project. Observing from the perspective of university students social obstacles, to explore college students social obstacles life status, mental status, analysis of college students in social problems, thus: (1) To help college students with social disabilities to overcome social barriers, reduce the college students from the school of college students with social disabilities fall into society is unable to adapt to today's social development need, is unable to survive in the society, so we want to help them in front of the college students entering society to overcome social barriers, reduce their head with society.(2) Cultivate college students' good social quality good social quality will give students bring positive influence on the life and work, let them have a better development in learning to work in the future, is also a modern society the demands of the new era of youth.

\section{The method of investigation}

Interview method. Project formally studied first before our psychological evaluation of each semester at school were tested in the students with a social disorder for more than two hours of detailed interviews, to understand their views and understanding of the social disorder, so as to further explore the factors influencing social barriers. The results of interviews using grounded theory analysis to extract the relevant knowledge about keywords on college students' social obstacles, there are these keywords designed questionnaire to collect data more widely to obtain materials to supplement and analysis.

Questionnaire. A survey of 300 college students nationwide was conducted by issuing questionnaires. In this paper, the paper analyzes the data of college students and analyzes the status of social obstacles in college students. Using the self-made college social disability evaluation scale, the author analyzes the social barriers of the subjects and makes good verification.

Study subjects. The study was limited to 400 undergraduates (half male and female) of the university of Harbin, aged 18 to 27 years of age. The survey, conducted over three months, gave special interviews to unspoken students.

\section{Research results and data analysis}

In total, there were 400 questionnaires, 394 and 380 valid questionnaires. There were 174 girls and 206 boys. The college freshmen, sophomores, juniors and seniors were able to recycle 20, 92, 159 and 110 valid questionnaires. The proportion was 5.26\%, 24.21\%, $41.58 \%$ and $28.94 \%$.

According to standards, the number of people who have no social disorder is 42.63 percent. With mild symptoms, 24.21 percent are likely to be bad. You're on the edge of a social phobia of 3.68\%. The number of people with a severe social phobia was 0.53 percent. On average, there is a person with a severe social disorder in every 200 college students; On average, one in 28 people is on the edge of social disorder; One in four people may develop into a social disorder. For China, which has 20 million college students, it is conceivable that the number of college students with social barriers is so great! And these change with social barriers are likely to become criminals, is the national social 
potential risks, so the current situation of Chinese college students social obstacles is not optimistic. The need for human intervention is necessary.

Table 1 percentage of social impairments

\begin{tabular}{ll}
\hline College students' social disorder severity & Percentage ge \\
\hline There is no social barrier & $42.63 \%$ \\
Mild social barriers & $24.21 \%$ \\
Moderate patients & $3.68 \%$ \\
Serious social barriers & $0.53 \%$ \\
\hline
\end{tabular}

The degree of internal and external to the character and social obstacles have significant negative correlation relationship, indicates that the easier to produce social disorder in personality month all social barriers and in patients with severe social obstacles on the edge of the college students, introversion accounted for $89.31 \%$.

In the history of social disorder, different grade is different, the sophomore social obstacles, the worst of the social disorder in patients with severe and $54.22 \%$ of the number of people that is on the brink of social disorder.

The results of the study. The social characteristics of college students: the social and social aspects of the social and social networking. First, as college students mature, they will become more and more eager and need to socialize. Second, in a new environment, college students need to establish their own relationships in a new environment and need to communicate with the new students around them. Once again, college students find jobs in society and need to socialize with new people. So social networking is imperative. With the development of the society communication between male and female students is more and more open, compared with the boys and girls relations to get everyone's identity, with puberty, the physical and psychological development makes the boys and girls the longing for love very, so college students present a more and more obvious social openness. With the development of the Internet, interpersonal communication is becoming more and more diversified, today's college students' social is not only face to face communication, most college students like to communicate through all kinds of social software, now almost every classmate's mobile phone can put one to two social software, such as WeChat, qq, etc. Therefore, the social networking of college students is extensive and contemporary.

The type of communication between college students: socializing with classmates and parents. Now in China most of the students in the university campus is the circle of life, so is sees most of the classmates and teachers every day, after entering the campus, the students first with students from all over the world, around the student's living habits and accent is a challenge, students need to constantly communicate to know each other, in the later study life will communicate constantly. Secondly, the students have to face the teacher every day in class. Again, the parents is the biggest logistical support of college students in the study period, fixed cost of living every month should have parents, at school I met what problem also can communicate with their parents for help.

\section{Suggestions and countermeasures}

Understand the social features of college life. From the moment we go to college, our social life has changed radically. Before university, everyone is simple and narrow social, the relationship between classmates is only a kind of expansion of friendship or close relationship, the communication between each other can only depend on their likes and dislikes to choose their own want to communicate, but by the university, we should not only learn how to communicate and oneself to like 
people and you don't like people to keep friendship, this is a prominent feature of college students' social. Therefore, it is important to understand the characteristics of college students' sociability in order to be able to learn more and more in the future.

Be aware of your own personality and cultivate it. In college, we can see that all the social people have something in common, which is that they are confident, open and enthusiastic, sincere and active. Therefore, in the university to learn their own personality shaping, for those with low self-esteem of students, must first learn to accept accept themselves, less for his own shortcomings to of have a little to compare with others, on the contrary, to foster strengths and circumvent weaknesses, promote their strengths to do things he is good at gradually build up confidence. People who are open and generous will exchange their studies. Be active, sincere and enthusiastic in your life so that you can keep expanding your circle of life.

Learn to master some social skills. Contacts as interpersonal skills in lubricant, it can help people in the communication activities to enhance communication and understanding each other, shorten the psychological distance, establish a good relationship. The psychological qualities of successful relationships include honesty, modesty, caution, kindness, respect for understanding, generosity, and so on. The use of language arts includes accurate expression, effective listening, polite manners and so on. College students in interpersonal interaction to establish self-confidence, improve their various aspects of quality, have the courage to practice, good at summary, practice in learning, learning in practice, constantly improve themselves, enrich ourselves, gradually to communication success, to success in life Of course no one is perfect, of course, we have made mistakes. Just we made a mistake at the same time we should timely adjust their mentality, remain the calm yourself, this is helpful for communication with others, make others understand and trust, so as to optimize their own social relations. Develop the ability to handle relationships and prepare for later life and work.

Strengthen the publicity about the relevant psychological knowledge of family and society. Social disorder is a result of many students don't have a good family environment and social environment, parents don't know what is social obstacles, to recognize the seriousness of the problem, don't know how to education and guide their children, with social disorder in the community's attention is not enough, did not give enough respect. Therefore, we need to science for parents to tell them what is social disorder and its harm, when a similar situation once children know how to correct the education and guidance of children, in order to avoid such consequences. Also want to strengthen the cognition of the society, make social disorder can get enough respect and concern, such ability in the family environment and social environment for social disorder gradually create a harmonious environment to help them return to normal life.

\section{Acknowledgment}

This work is supported by.Innovative Entrepreneurship Training Program for College Students: A Study on Social Barriers of College Students (201610240009).

\section{References}

[1] Kongxiang Zhu. University freshmen anxiety and social, anxiety analysis analysis. Chinese national Medical journal. 2003,15(1).

[2] Weilin Zhou. Master's thesis in China: assessment of social effectiveness of college students and social anxiety, University of suzhou, 2005.

[3] Ollendick, T.H, Hirshfeld, Beckerk, D.R.T he developmental ychopathology of social anxiety disorder. Biology Psychiatry, 2002, 51:44-58.

[4] Liu Henin. Freud's theory of anxiety. Journal of the education college, 2009,25 (1).

[5] Peng pu-zi. Research on the study of social anxiety in college students: university of central south university, 2003. 